\title{
Miheil Cavahişvili’nin “Lambalo ve Kaşa” romanındaki Türkçe kelime ve ifadelerin incelenmesi
}

\section{Gül Mükerrem ÖZTÜRK1}

\begin{abstract}
APA: Öztürk, G. M. (2019). Miheil Cavahişvili’nin "Lambalo ve Kaşa” romanındaki Türkçe kelime ve ifadelerin incelenmesi. RumeliDE Dil ve Edebiyat Araştırmaları Dergisi, (15), 479-504. DOI: $10.29000 /$ rumelide.580713
\end{abstract}

\section{$\ddot{O} \mathbf{z}$}

18. ve 19. yüzyıllarda Kafkas halkları arasında Gürcistan'ın kültürel bir ülke olarak benimsenmesi ve bu dönemde edebiyat uğraşlarının daha çeşitli ve güçlü olması Azerice, Farsça, Osmanlıca ve Arapça birçok el yazmalarının bulunması ve yazılması oldukça dikkat çekicidir. Bulunduğu konumundan dolayı güneydoğuda Azerbaycan Türkleri, güneybatıda Türkiye Türkleri ile komşu olan Gürcistan'ın dilsel açıdan komşularından etkilendiği görülmektedir. Buradan hareketle makalemizdeki amaç, Gürcü yazar Miheil Cavahişvili’nin 1925 yılında Gürcüce yazdığı "Lambalo ve Kaşa” adlı eseri, Fahrettin Çiloğlu'nun 2018 yılında Türkiye Türkçesine çevirdiği tercümesi ile karşılaştırılarak söz konusu dil etkileşiminin örneğini ortaya koymaktır. Makalede ilk olarak Miheil Cavahişvili hakkında biyografik ve edebi bir değerlendirme yapılmış ve "Lambalo ve Kaşa" adlı eserin içeriği hakkında bilgi verilmiştir. Urmiye Gölü çevresinde geçen ve Rus Çarlığı'nın din kardeşliği üzerinden yürüttüğü politikayı ele aldığı eserin Gürcüce orijinali incelendiğinde Azerbaycan Türkçesine ait kelime ve ifadenin orijinali korunarak Gürcü alfabesi ile yazıldığı tespit edilmiştir. Sonrasında aynı inceleme Çiloğlu'nun tercümesi için yapılmış, söz konusu kelimelerin bir kısmının günümüz Türkiye Türkçesine çevrildiği görülürken, bir kısmının Azerbaycan Türkçesi 'de kullanıldığı hali ile muhafaza edildiği görülmüştür. Sonuç olarak yapılan "Lambalo ve Kaşa”nın karşılaştırmalı incelemesine dayanarak alfabesi, dil yapısı ve sisteminde farklıklar olan Türkçe ve Gürcücenin edebi kullanımlarında ortak kelimelerin mevcudiyetleri belirlenmiş, eserin yazıldığı dönemde Gürcü edebiyatındaki Türkçe etkisi ortaya koyulmuştur.

Anahtar kelimeler: Miheil Cavahişvili, "Lambalo ve Kaşa", Azerbaycan Türkçesi, Türkiye Türkçesi.

\section{The investigation of Turkish words and expressions in Miheil Cavahişvili's novel "Lambalo and Kașa"}

\begin{abstract}
It is quite striking that among the Caucasian peoples in the 18th and 19th centuries, the adoption of Georgia as a cultural country. The fact that there were a variety of literary works in this period, and the existence and writing of many manuscripts in Azerbaijani, Persian, Ottoman and Arabic is also important. Due to the location, it is seen that Georgia is affected in terms of their linguistic features from its neighbours: Azerbaijani Turks in the southeast and in Turkey Turks in the southwestern. From here, the purpose of our article is to show an example of a language interaction by comparing the work called "Lambalo and Kaşa" written by Georgian writer Mikheil Cavahişvili in Georgian in 1925 with its translation into Turkish by Fahrettin Çiloğlu in 2018. In the article, a biographical and literary evaluation was made about Miheil Cavahishvili and information about the content of the work
\end{abstract}

1 Dr. Öğr. Üyesi, Recep Tayyip Erdoğan Üniversitesi, Fen Edebiyat Fakültesi, Gürcü Dili ve Edebiyatı Bölümü (Rize, Türkiye), gul.ozturk@erdogan.edu.tr, ORCID ID: oooo-0003-4730-6720 [Makale kayit tarihi: 27.02.2019-kabul tarihi: 14.06.2019; DOI: 10.29000/rumelide.580713] 
named "Lambalo and Kaşa" was given. When the Georgian original was examined, it was determined that words and expressions belonging to Azerbaijani Turkish were preserved in Georgian alphabet by preserving the original. Later on, the same examination was made for Çiloğlu's translation and it is seen that some of the words were translated into Turkey Turkish, some of them used as they were in Azerbaijani Turkish. In conclusion, based on the comparative study of "Lambalo and Kaşa", the existence of common words in the Turkish and Georgian literary uses, which have differences in the alphabet, language structure and system, were determined and the influence of Turkish in Georgian literature was revealed.

Keywords: Miheil Cavahişvili, "Lambalo and Kaşa", Azerbaijani Turkish, Turkey Turkish.

\section{Giriș}

\section{Miheil Cavahişvili’nin hayatı ve edebi yönü}

20. yüzyıl Gürcü edebiyatının önemli kurucularından Miheil Cavahişvili 1880 yılında Gürcistan'ın başkenti Tiflis'in güneyinde Şerakva köyünde doğmuştur. Varlıklı bir köy ailesinin çocuğu olan Miheil babasının ısrarı üzerine Kırım'daki bağcılıkla ilgili bir yüksekokula göndermiştir. Daha lise yıllarında şiirler ve öyküler yazan Cavahişvili, yazar olmayı amaçladığından bă̆cılık mesleğini sevememişti. Kırım'da öğrenimini sürdürürken ailesinin maruz kaldığı bir trajediden dolayı okulu yarıda bırakmak zorunda kalmıştır. Bundan dolayı 1901 yllında Miheil Cavahişvili köyüne geri dönmüş ve bağ ve bahçe işlerinin başına geçmiştir. Bu esnada halk kitlelerinin savunuculuğu üzerine yazdığı yazılar üzerine iktidarın baskılarına maruz kalan Cavahişvili, Fransa'ya kaçarak 1907 yllında ülkesini terk etmek zorunda kalmıştır. Fransa'da Paris Üniversitesi Edebiyat Fakültesi’ne girmiş ve buradaki öğrenimini tamamladıktan sonra 15 yll hiç eser vermemiştir. 1913 yllına kadar Rostov-na-Donu'da yaşamış ve o yıl ülkesine geri dönmüştür. 1921 yılında Bolşevikler tarafından işgal edilmiş olan Gürcistan'ın bağımsızlı̆̆ının geri kazanması için verilen ulusal mücadelenin önderlerinden biri olduğu için 1923’te tutuklanıp idam cezasına çarptırılmış ve yazarlar birliğinin araya girmesiyle serbest bırakılmıştır. 14 Ağustos 1937 ylında tutuklanıp kurşuna dizilmiştir.

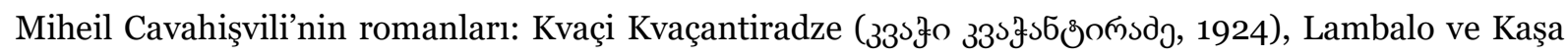

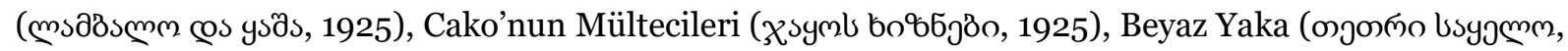

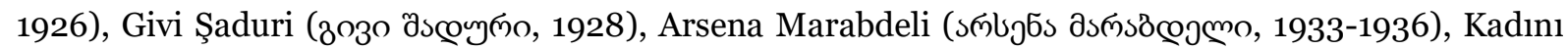

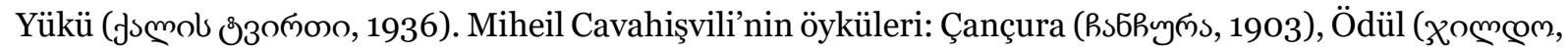

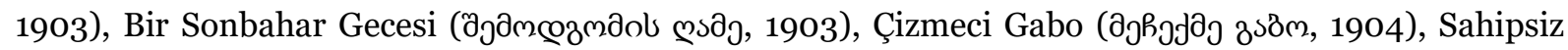

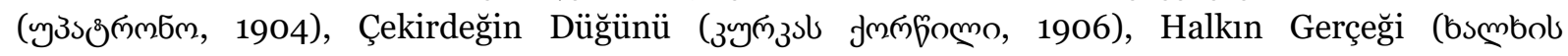

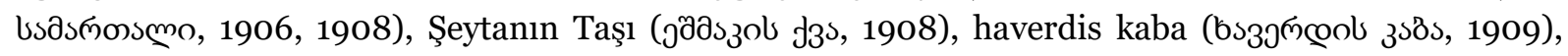
Tetiebi (

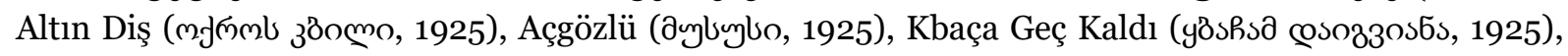

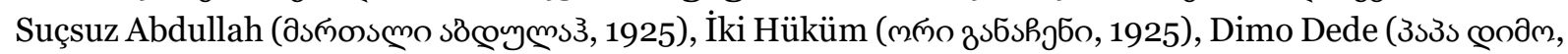

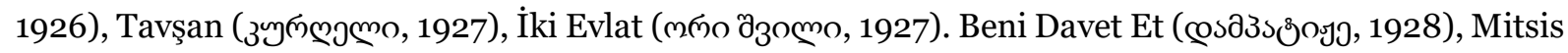
Kvili (aofol yozomo, 1928), Fincan (öобхз5о, 1929).

Yazarın Türkçe’ye çevrilen ilk yapıtı gadszol j3 ( Şeytanın Taşı, çeviren: İbrahim Yavuz Goradze,

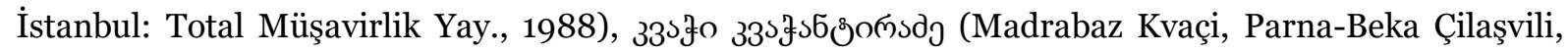

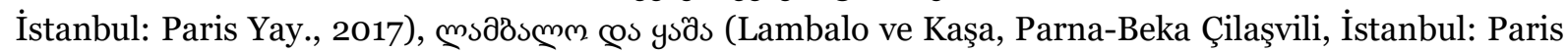
Yay., 2018). 


\section{Miheil Cavahișvili’nin “Lambalo ve Kașa” adlı eseri}

Miheil Cavahişvili "Lambalo ve Kaşa" adlı eseri 1925 yılında kaleme almıştır. Bu dönemde Sovyet Gürcistan'ı çok şiddetli bir savaş içerisindeydi. Kanlı günlerden sonra geriye kalan acılar Miheil Cavahişvili'nin kalbinde derin bir şekilde iz bırakmış ve bu olayların izinde, Miheil Cavahişvili, Gürcistan'ın düştüğü bu durumu hikâyelerinde de açıcça hissettirmektedir. Eser Urmiye Gölü çevresinde geçmişte Medlerin, Asurilerin, Azerilerin, Gürcülerin, Ermenilerin, Rusların vb. farklı din ırkların bir arada yaşamaktaydı ve Birinci Dünya Savaşı'nın son dönemlerinde Kızılhaç ordusu tarafından gönderilen bir Gürcü doktorun ağzından anlatılan bir hikâyedir. Başlı̆̆ından da görüldüğü gibi Lambalo ve Kaşa adında 2 temel karaktere yer verilmiştir. Lambalo, iyiliğgi; Laşa ise kötülüğü sembolize etmektedir. Lambalo; Azerice melodik, kafiyeli, güzel anlamına gelmektedir. Bahsettiğimiz Gürcü Doktor, Lambalo lakaplı Meşhedi (Gürcüce eserdeki ismi: dsð̋̋sœoo ”Maşhadi”) Hasan isimli genç bir Azeri ile tanışmaktadır. Aralarında dostluk oluşmaktadır. Gürcü Doktor, Lambalo’ya düşmanlık besleyen Kaşa Lazare adlı bir Asuri'den korumaya çalışmaktadır. Rus Ortodoksu başkanı Piskopos Pavle de Kaşa Lazare'ye arkada çıktığından ve Urmiye Şehrinin valisini bu olaylara seyirci kalması Gürcü doktorun Lambalo’yu daha da koruma içgüdüsüne itecektir. Hikâyede iyiliğin ve kötülüğün birbirleriyle savaş içerisinde olduklarında bahsedilmektedir. Sadece yazarın öncülük ettiği zamanda değil genel bir zaman dilimi içinde de savaş, karakteristik bir durumdur. Hikâye ilk ağzından devam etmektedir. Ancak, kader-piyanist Katha'yı canlı bırakmayacak. Domateslerden birinin gönderdiği bir ısırık yılanı ile ölecek. Bununla birlikte, adaletin sembolü olan doktor, tüm suçları önemsemez ve onu kurtarmak için her şeyi yapar. Bütün bunlardan sonra, anlatıcı anavatanına geri dönmeye karar verir.

\section{Lambalo ve Kaşa Romanının Şahıs Kadrosu}

Kızıl Haç Doktoru : Ana karakter

Maşadi Hasan : Lambalo

Pavle : Piskopos

Kaşa Lazare : Rahip, piskoposun uşağı

Bekauri : İran'da başından sorumlu bir doktorun bekçisi

Piskopos Pavel : Urmiye’deki Rus Ortodoks misyonu

Meşhedi İzzet : Lambalo’nun babasıdır. “Yılan ailesi”ne mensuptur.

İtimadü’d-Devle : İranın Urmi’ye valisi

General Çernozubov : Urmiye'deki Rus ordusu komutanı

Doktor Shedd : Urmiye'deki Amerikalı misyoner

Kumandan Berezovski : Urmiye şehri kumandanı

Konsolos Nerotov : Rusya’nın Urmiye Konsolosu

Zekiye : Lambalo’nun eşi 


\section{Romanında geçen Türkçe kelime ve ifadeler}

Türk - Gürcü münasebetlerinin günümüzde tekrar canlandığından söz edilebilir. Bu münasebetler, sahip olduğu tarihi derinlikle birlikte, her iki milletin dilinin birbiriyle etkileşimini tesis ederek her iki dil arasında birçok sözcük alışverişinin gerçekleşmesini sağlamıştır. Gürcüceye Türkçeden geçen sözcüklerde, Gürcistan'da tarih boyunca varlık göstermiş olan Anadolu Türkçesi, Azeri Türkçesi ve Karaçay Balkar gibi Kafkasya'da konuşulan farklı Türk lehçelerinin izlerinin bir arada görülmesi ilgi çekicidir (Janashia 2010: 116) "Lambalo ve Kaşa" adlı eserden Azerbaycan Türkçesi ve Türkiye Türkçesine ait kelimeler sıralanmıştır ve derlenen kelimler aşağıdaki tabloda Gürcücedeki şekli, Türkçdeki şekli Azerbaycan ve Türkiye Türkçesindeki şekli karşılaştırmalı olarak sunulmuş ve TürkçeGürcüce anlamı ifade edilmiştir.

\begin{tabular}{|c|c|c|c|c|}
\hline $\begin{array}{l}\text { Orijinal } \\
\text { Metindeki } \\
\text { Kelimeler } \\
\text { (Gürcüce) }\end{array}$ & $\begin{array}{l}\text { Orijinal } \\
\text { Metindeki } \\
\text { Kelimelerin } \\
\text { Okunuşu }\end{array}$ & $\begin{array}{l}\text { Hedef Metne } \\
\text { Aktarilan } \\
\text { Kelimeler } \\
\text { (Türkçe) }\end{array}$ & $\begin{array}{l}\text { Türkçedeki } \\
\text { Anlamı }\end{array}$ & Gürcücedeki Anlamı \\
\hline 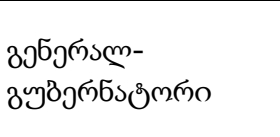 & $\begin{array}{l}\text { General- } \\
\text { Gubernatori }\end{array}$ & Genel Vali & $\begin{array}{l}\text { Türkçe: Genel Vali } \\
\text { Azerice: Umumi } \\
\text { qubernator }\end{array}$ & 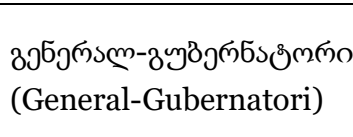 \\
\hline 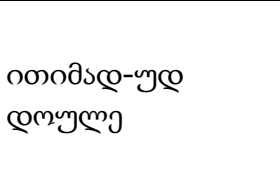 & itimadüd- Dövle & İtimadü'd-Devle & $\begin{array}{l}\text { Osmanlıca: } \\
\text { I’timadü'd-Devle } \\
\text { Azerice: İtimadüd- } \\
\text { Dövle }\end{array}$ & 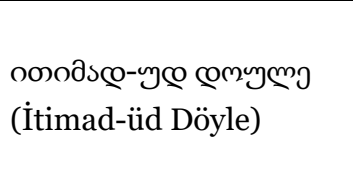 \\
\hline 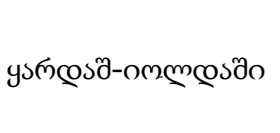 & Q'ardaş-yoldaşi & Kardeş & $\begin{array}{l}\text { Türkçe: kardeş } \\
\text { Azerice: qardaş }\end{array}$ & 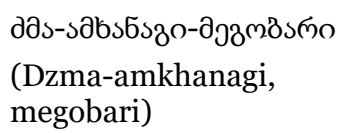 \\
\hline 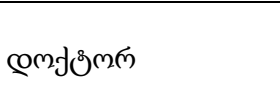 & Doktor & Doktor & $\begin{array}{l}\text { Latince : Doktor } \\
\text { Azerice : Doktor }\end{array}$ & $\begin{array}{l}\text { ołodo } \\
\text { (Ekimi) }\end{array}$ \\
\hline scms3 & Alah & Allah & $\begin{array}{l}\text { Arapça : Allah } \\
\text { Azerice: Allah }\end{array}$ & $\begin{array}{l}\text { мадпоо } \\
\text { (Ğmerti) }\end{array}$ \\
\hline sলs & Ağa & Ağa & $\begin{array}{l}\text { Türkçe : Ağa } \\
\text { Azerice: Ağa }\end{array}$ & 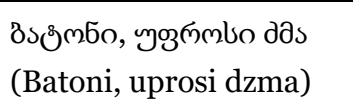 \\
\hline omen 39 & Yol ver & Yol ver & $\begin{array}{l}\text { Türkçe: Yol ver } \\
\text { Azerice: Yol ver }\end{array}$ & 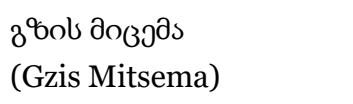 \\
\hline 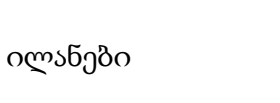 & İlanebi & Yllanlar & $\begin{array}{l}\text { Türkçe: Yllanlar } \\
\text { Azerice: İlanebi }\end{array}$ & $\begin{array}{l}\text { З3эмलэठ̈о } \\
\text { (Gvelebi) }\end{array}$ \\
\hline Зso zoøon! & Hai gidi! & Hey gidi! & $\begin{array}{l}\text { Türkçe: } \\
\text { Hey gidi! }\end{array}$ & $\begin{array}{l}\text { 3̌s zo@o! } \\
\text { (Hey Gidi!) }\end{array}$ \\
\hline ms оzоoо! & ms ozoon! & Yiğit & $\begin{array}{l}\text { Türkçe: Yiğit } \\
\text { Azerice: İgid }\end{array}$ & 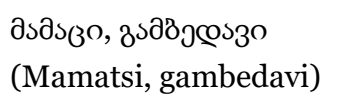 \\
\hline вуэ๓хо & Gurci & Gürcü & $\begin{array}{l}\text { Türkçe: Gürcü } \\
\text { Azerice: }\end{array}$ & 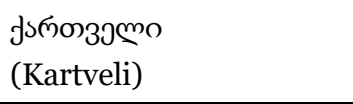 \\
\hline jмозь-ммемо! & Kopa-oğli! & İt oğlu it & Türkçe: köpe’koğlu- & dsçmol $\tilde{y}_{3}$ омо \\
\hline
\end{tabular}




\begin{tabular}{|c|c|c|c|c|}
\hline & & & (kaba konuşmada) & (Dzağlis Şvili) \\
\hline 3 & Valah! & Valla! & Vallahi & 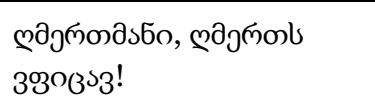 \\
\hline $3^{\mathrm{s}} \mathrm{mo}$ & Vali & Vali & $\begin{array}{l}\text { Türkçe: Vali } \\
\text { Azerice:Qubernator }\end{array}$ & 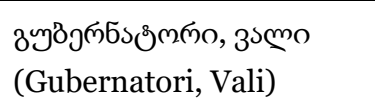 \\
\hline 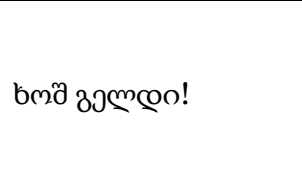 & Hoş geldi! & Hoş geldin! & $\begin{array}{l}\text { Türkçe: Hoş geldin! } \\
\text { Azerice: Xoş } \\
\text { gəlmisiniz! }\end{array}$ & 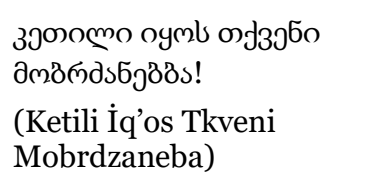 \\
\hline usäsb bjon mলnluy 6 ! & Sabah heir olsun! & Sabah heir olsun! & $\begin{array}{l}\text { Türkçe: Günaydın, } \\
\text { Hayırlı Sabahlar! } \\
\text { Azerice: Sabahınız } \\
\text { xeyir / Sabahın xeyr. }\end{array}$ & 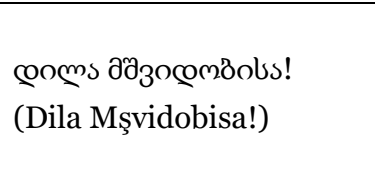 \\
\hline 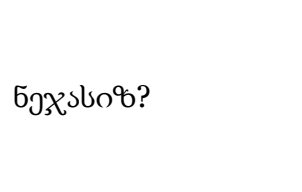 & Nejasiz? & Nasilsınız? & $\begin{array}{l}\text { Türkçe: Nasılsınız? } \\
\text { Azerice: necəsən? }\end{array}$ & 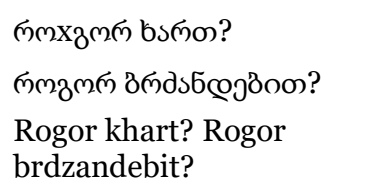 \\
\hline 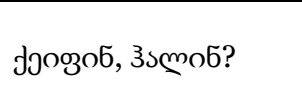 & Keipin, halin? & İyi misiniz? & $\begin{array}{l}\text { Türkçe: İyi misiniz? } \\
\text { Azerice: Yaxşısanmı? }\end{array}$ & 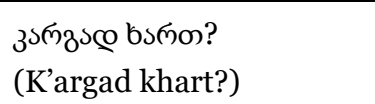 \\
\hline yмбsмूо & Konaği & Misafir & $\begin{array}{l}\text { Türkçe: Misafir } \\
\text { Azerice: Qonaq, } \\
\text { Mehman, Müsafir }\end{array}$ & 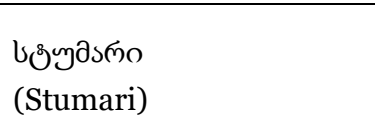 \\
\hline 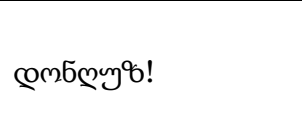 & Donguz! & Domuz! & $\begin{array}{l}\text { Türkçe: Domuz } \\
\text { Azerice: Donuz, } \\
\text { domuz }\end{array}$ & $\begin{array}{l}\text { लмпюо } \\
\text { (ğori) }\end{array}$ \\
\hline 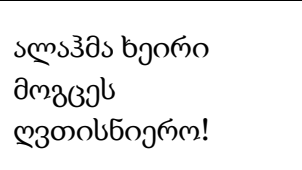 & $\begin{array}{l}\text { Allahma heir } \\
\text { mogtses ğvtisniero! }\end{array}$ & $\begin{array}{l}\text { Allah sizden razı } \\
\text { olsun! }\end{array}$ & $\begin{array}{l}\text { Türkçe: Allah sizden } \\
\text { razı olsun! } \\
\text { Azerice: Allah sizden } \\
\text { razı olsun! }\end{array}$ & 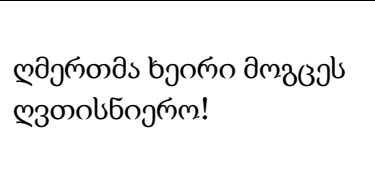 \\
\hline 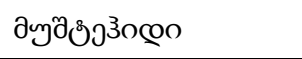 & Müştehidi & Din âliminiz & Müctehid-din alimi & 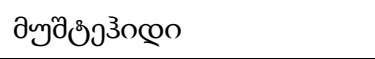 \\
\hline słodฉsð̃os & Akimbaşia & Hekimbaşı & $\begin{array}{l}\text { Türkçe: Hekimbaşı } \\
\text { Azerice: Həkimbaşı }\end{array}$ & 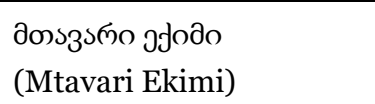 \\
\hline 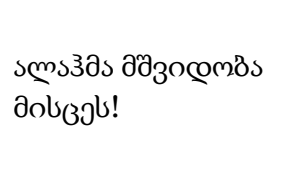 & $\begin{array}{l}\text { Allahma Mşvidoba } \\
\text { mitses! }\end{array}$ & $\begin{array}{l}\text { Allah ondan razı } \\
\text { olsun! }\end{array}$ & $\begin{array}{l}\text { Türkçe: Allah razı } \\
\text { olsun! } \\
\text { Azerice: Allah razı } \\
\text { olsun! }\end{array}$ & 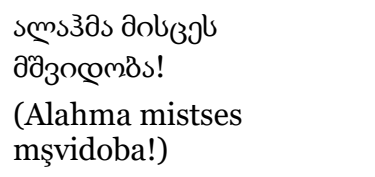 \\
\hline 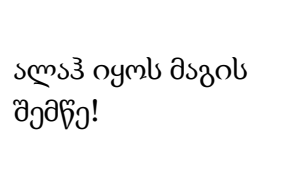 & $\begin{array}{l}\text { Allah ikos magis } \\
\text { şemtse! }\end{array}$ & $\begin{array}{l}\text { Allah onun } \\
\text { yardımcisı olsun! }\end{array}$ & $\begin{array}{l}\text { Türkçe: Allah onun } \\
\text { yardımcısı olsun! } \\
\text { Azerice: Allah } \\
\text { kömekçisi olsun! }\end{array}$ & 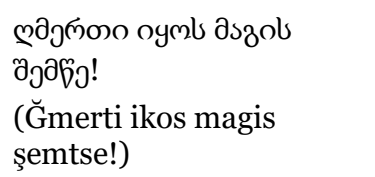 \\
\hline so ठ̀sলnsa! & Ay Balam! & Ay balam! & $\begin{array}{l}\text { Türkçe: Bebeğim, } \\
\text { güzelim, yavrum! } \\
\text { Azerice: Ay balam, } \\
\text { balam! }\end{array}$ & 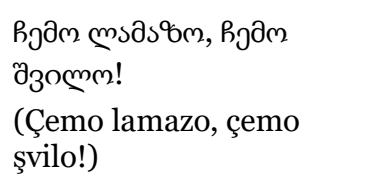 \\
\hline $\begin{array}{l}\text { Rмb изммм, sмs, } \\
\text { Rмb! }\end{array}$ & çoh sağol, ağa, çoh! & $\begin{array}{l}\text { Çok sağ ol, ağa, } \\
\text { çok! }\end{array}$ & $\begin{array}{l}\text { Türkçe: Çok sağ ol, } \\
\text { ağa, çok! } \\
\text { Azerice: Çox sağ ol. }\end{array}$ & 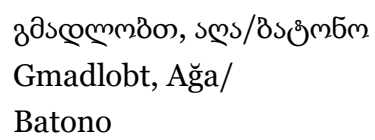 \\
\hline
\end{tabular}


484 / RumeliDE Journal of Language and Literature Studies 2019.15 (June)

The investigation of Turkish words and expressions in Miheil Cavahişvili’s novel "Lambalo and Kaşa”/ G. M. Öztürk (p. 479-486)

\begin{tabular}{|c|c|c|c|c|}
\hline виупূs & Burda & Burada & $\begin{array}{l}\text { Türkçe: burada } \\
\text { Azerice: Burada }\end{array}$ & $\begin{array}{l}\text { sf } \\
(\mathrm{Ak})\end{array}$ \\
\hline бsдs\%o & Namazi & Namaz & $\begin{array}{l}\text { Türkçe: Namaz } \\
\text { Azerice: Namaz }\end{array}$ & $\begin{array}{l}\text { m(33s } \\
\text { (Lotsva) }\end{array}$ \\
\hline 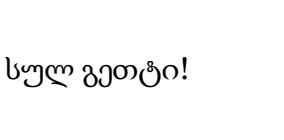 & Sul getti! & Su çıktı! & $\begin{array}{l}\text { Türkçe: } \\
\text { Su geldi/çıktı } \\
\text { Azerice: Su çıxdı. }\end{array}$ & $\begin{array}{l}\text { Øуsмо дмзоœь } \\
\text { (Tskali movida) }\end{array}$ \\
\hline on!.. s6sbo6o!.. & İt, anasını! & İt, anasını! & $\begin{array}{l}\text { Türkçe: İt, anasını! } \\
\text { Azerice: Köpək, it, } \\
\text { anasını! }\end{array}$ & 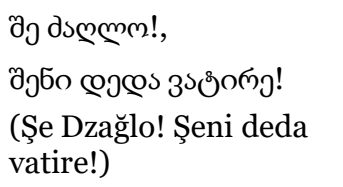 \\
\hline 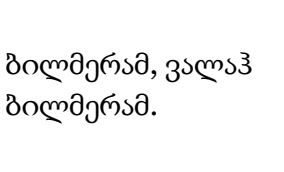 & $\begin{array}{l}\text { Bilmeram, valah } \\
\text { bilmeram. }\end{array}$ & $\begin{array}{l}\text { Bilmiyorum, } \\
\text { vallahi } \\
\text { bilmiyorum. }\end{array}$ & $\begin{array}{l}\text { Türkçe: Bilmiyorum, } \\
\text { vallahi bilmiyorum. } \\
\text { Azerice: Bilmeram, } \\
\text { valah bilmeram. }\end{array}$ & 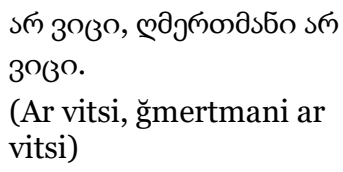 \\
\hline moбo & oini & Oyun & $\begin{array}{l}\text { Türkçe: Oyun } \\
\text { Azerice: Oyun, } \\
\text { tamaşa }\end{array}$ & osว১ð̃o (Tamaşi) \\
\hline yo\%o & Kızi & $\mathrm{K} ı \mathrm{z}$ & $\begin{array}{l}\text { Türkçe: Kız } \\
\text { Azerice: Qız }\end{array}$ & 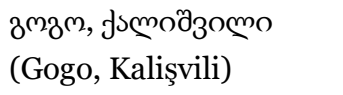 \\
\hline msosson! & Lazat! & Lezzetli & $\begin{array}{l}\text { Türkçe: Lezzet! } \\
\text { Azerice: Ləzzət! }\end{array}$ & $\begin{array}{l}\text { әəдэ๓оэмп! } \\
\text { (Gemrieli!) }\end{array}$ \\
\hline Bsmsz's scosanostos & Balaca Adamiani & Küçük bir adam & $\begin{array}{l}\text { Türkçe: Küçük adam } \\
\text { Azerice: Balaca insan }\end{array}$ & 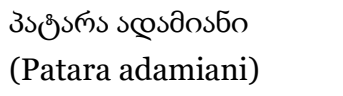 \\
\hline 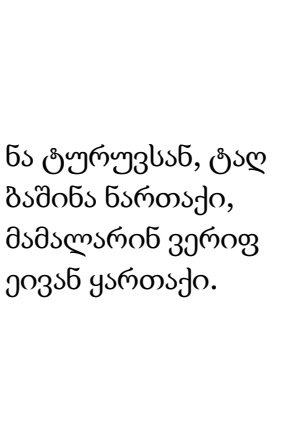 & $\begin{array}{l}\text { Na turuvsan, tă } \\
\text { başina nartaki, } \\
\text { mamalarin verip } \\
\text { yevan kartaki. }\end{array}$ & $\begin{array}{l}\text { Bu dağda maral } \\
\text { gezer, telini tarar } \\
\text { gezer. }\end{array}$ & $\begin{array}{l}\text { Orijinal metnin } \\
\text { Türkçe anlamı } \\
\text { maalesef birebir } \\
\text { uyuşmadığından } \\
\text { Çevirmen burada } \\
\text { farklı anlam içeren } \\
\text { İbrahim Yıldırım’ın } \\
\text { söylediği “Bu dağda } \\
\text { meral gezer” } \\
\text { türküsünü Türkçe } \\
\text { tercümesi olarak } \\
\text { aktarmıştır. }\end{array}$ & $\begin{array}{l}\text { Gürcücede bu ifade yer } \\
\text { almaktadır. }\end{array}$ \\
\hline Ямb пs\%osa. & Çokh raziam. & Teşekkür ederim. & $\begin{array}{l}\text { Türkçe: Teşekkür } \\
\text { ederim. / çok } \\
\text { memnunum. } \\
\text { Azerice: Çok raziam / } \\
\text { Çok memnunum. }\end{array}$ & 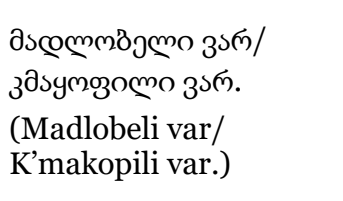 \\
\hline jмаsঞ эলms-s-s! & Komag elaa! & Yardım et! & $\begin{array}{l}\text { Türkçe: Yardım edin! } \\
\text { Azerice: Kömək ele! }\end{array}$ & 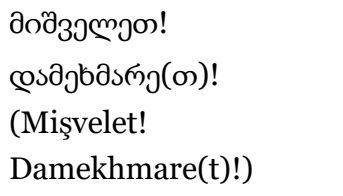 \\
\hline 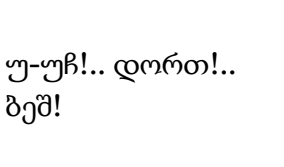 & U-uç!. Dort!.. Beş! & Ü-üç! Dört! Beş! & $\begin{array}{l}\text { Türkçe: Ü-üç! Dört! } \\
\text { Beş! } \\
\text { Azerice: Ü-üç! Dört! } \\
\text { Beş! }\end{array}$ & $\begin{array}{l}\text { Łsao! monbo! byono! } \\
\text { (Sami! Otkhi! Khuti!) }\end{array}$ \\
\hline
\end{tabular}




\begin{tabular}{|c|c|c|c|c|}
\hline 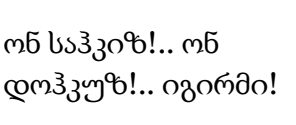 & $\begin{array}{l}\text { On sahkiz!... on } \\
\text { dohkuz!... igirmi! }\end{array}$ & $\begin{array}{l}\text { On sekiz! On } \\
\text { dokuz! Yirmi!” }\end{array}$ & $\begin{array}{l}\text { Türkçe/Azerice: On } \\
\text { sekiz! On dokuz! } \\
\text { Yirmi!” }\end{array}$ & 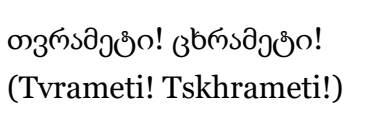 \\
\hline 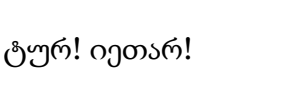 & Tur! Yetar! & Dur! Yeter! & $\begin{array}{l}\text { Türkçe: Dur! Yeter! } \\
\text { Azerice: Dur! yetər! }\end{array}$ & 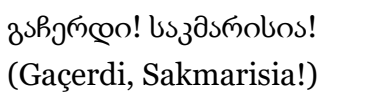 \\
\hline оэ\% วলms! & Tez ela! & Acele edin! & $\begin{array}{l}\text { Türkçe: Acele edin! } \\
\text { Azerice: Tez əle! }\end{array}$ & $\begin{array}{l}\text { œshfృ๓ூon! } \\
\text { (Daçkaret!) }\end{array}$ \\
\hline ঢsলssason mলn! & Salamat ol! & Hoşça kal! & $\begin{array}{l}\text { Türkçe: Hoşça kal! } \\
\text { Azerice: Salamat qal } \\
\text { (ol)! }\end{array}$ & 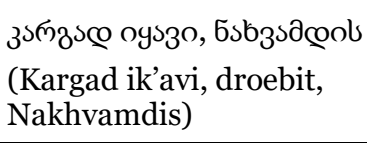 \\
\hline 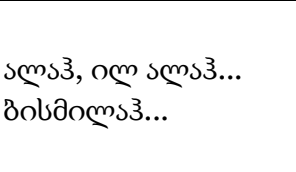 & $\begin{array}{l}\text { Allah, İlalah, } \\
\text { Bismilah }\end{array}$ & $\begin{array}{l}\text { La ilahe illallah... } \\
\text { Bismillah. }\end{array}$ & $\begin{array}{l}\text { Türkçe: La ilahe } \\
\text { illallah... Bismillah. } \\
\text { Azerice: La ilahe } \\
\text { illallah... Bismillah. }\end{array}$ & Gürcücede yok \\
\hline
\end{tabular}

\section{Sonuç}

Gürcü, Türk ve Azeri halkları arasındaki yüzyllar boyu devam eden ilişkiler, başta kelime düzeyinde olmak üzere birbirlerinden alıntı kelimelerin var olmasından kaynaklanmaktadır. Ekonomik, politik ve kültürel etkenler dil etkileşimin yadsınamaz bir gerçeğidir. Ulusların birbirleriyle sürekli, teknik, bilimsel ve kültürel ilişkiler halinde bulunmalarından ötürü karşılıklı olarak dillerine birçok yeni ve yabancı sözcükleri almalarına neden olmaktadır. Gürcüceye giren yabancı sözcüklerin varlığı, anayurttan uzun zaman kopmuş bulunan ve bugünkü modern Gürcü literatürünü izleme olanağı olmayan ırkdaşlarımızın dikkatini çekmektedir.

Miheil Cavahişvili'nin "Lambalo ve Kaşa" adlı bu eseri edebi yaşamındaki önemli eserlerinden biridir. Ayrıca bu eser onun mükemmel içsel sanatsal yönünü de ortaya koymaktadır. Eserde bazı kriterlerin olduğunu söyleyebiliriz. Yazar hikâyeyi değerlendirirken bütün kriterleri göz önünde bulundurarak hikâyenin değerini yüksek tutmaya çalışmıştır. Bilinen diğer türlerden farklı etki yaratan bir hikâyedir. Bu çalışmamızda Gürcü yazar Mikheil Cavahişvili tarafından 1925 yılında kaleme alınan ve 2018 yllında Parna Beka Çilaşvili tarafından Türkçeye çevrilen "Lambalo ve Kaşa” adlı ünlü eserinin karşılaştırmalı olarak ele alarak orijinal (Gürcüce metin) metinde yer alan Azerbaycan Türkçesi’nin hedef metne (Türkçe metin) aktarılışını karşılaştırmalı olarak ele aldık. İnceleme esnasında tablo halinde kelimelerin Türkiye Türkçesinde, Azerbaycan Türkçesinde ve Gürcü dilinde nasıl olması gerektiğini belirttik. Buradaki amaç orijinal metin Gürcü dilinde olduğundan eserde yer alan Azerbaycan Türkçesindeki ifadelerin Gürcücede nasıl olabileceğini de belirtmiş̧ olduk. Eserde yer alan Türk kökenli kelimelerin incelenmesi sonucunda tablodan da anlaşıldığı gibi şöyle bir sonuca varmış olduk. Örneğin: Donguz-a

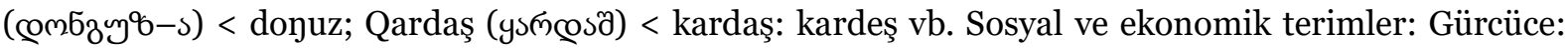
ağa, Türkçe: ağa vb. Yine eserde "Ekimi” kelimesi yer almaktadır. "Ekimi” kelimesi Gürcüceye daha sonraki ylllarda geçmiştir. "Ekimi” kelimesi, Gürcüce sözlüklerde XV. yüzyılda Osmanlı hâkimiyeti döneminden itibaren görülmektedir. Gürcüce akimi/ekimi; Türkçe: hekim „doktor, hastaya bakan kişi Gürcüce akimbaşi/ekimbaşi „tıp uzmanı olmayan, kurşuncu, üfürükçü, doktor yardımcısı ${ }^{\text {"e }}$ Türkçe hekim başı/hakimbaşı „baş doktor" anlamına gelmektedir. Orbeliani’nin „Leksikoni Kartuli“de (Gürcüce Sözlügü) kelime Arapça olarak belirtilmektedir. Gürcüce yazılı eserlerde XII. yüzyıl, özellikle de XVI. yüzylldan bu yana Anadolu Türkçesinden ve Azericeden, Gürcüceye geçmiş Türkçe kelimeler vardır. Gürcü folkloruna ve diline Türkçeden geçmiş kelimelerin çoğu Türk dili ailesinin Oğuz 
(Osmanlıca, Türkçe, Azerice) ve Kıpçak (Karaçayca, Kumukça) gruplarına ait kelimelerden oluşmaktadır.

"Lambalo ve Kaşa” adlı eserde Gürcü doktor 'un Lambalo (Azeri Genç)'ya Gürcüce selam vermesi ve Lambalo'nun Gürcü doktora eserde Tatarca cevap vermesi ilginç bir durumdur. Genel olarak Cavahişvili Avrupa'da eğitim aldığı için birkaç dil biliyordu. Fakat büyüdüğü yer Borçkhalo olduğu için orada Azerice konuşuyorlardı ve bu dili de gayet iyi biliyordu. Bundan dolayı olsa gerek hedef metinde çevirmen Lambalo'nun Tatarca değil de Azerice olarak dile getirmektedir. Bilindiği üzere Tatar kelimesi „müslüman“e anlamındadır. Ancak Gürcüce eserlerin çoğunda Tatar „Moğole anlamında da kullanılmaktadır. Farklı yayınlarda Tatarca yerine Türkçe yazıldığı görülmektedir. Buradan hareketle bu dil üzerine kendi bilgisini kullandığını ve eserdeki Gürcü doktorun burada Azerice ifadelere yer verdiğini söyleyebiliriz. "Türkiye'de Halk Ağzından Derleme Sözlüğü, I-XI” adlı eserden yaptığımız inceleme sonucunda Türkiye Türkçesi ağızlarında yaklaşık yüz on yedi Gürcüce sözcük tespit edilmiştir. Bu kelimeler, Gürcü alfabesiyle yazımları, anlamları ve hangi Türkiye Türkçesi ağızlarında kullanıldığı ifade edilerek sıralanmıştır. Bazı Türkçe kökenli olan kelimeler Gürcüceye Türkçe aracılığıyla girmiştir.

\section{Kaynaklar}

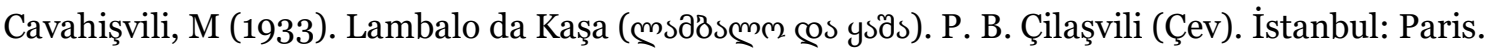

Janashia, M. (2010). Gürcü Dilindeki Türkçe Kökenli Özel İsimler, Ankara Üniversitesi Dil ve TarihCoğrafya Fakültesi Türkoloji Dergisi, 17, 2, s.115-129, Ankara.

Türk Dili Kurumu. (2011). Türkçe Sözlük. (11.baskı). Ankara: TDK.

Türk Dili Kurumu. (2012). Yazım kılavuzu. (27.baskı). Ankara: TDK.

tr.wikipedia.org. Lambalo da Kaşa-Vikipedi. 